\title{
A simple and useful option for treatment of acute type A dissection with the tear beyond the aortic arch
}

\author{
Kazuhito Imanaka, MD, Shunei Kyo, MD, Masaaki Kato, MD, Hiroaki Tanabe, MD, \\ Hiroshi Ohuchi, MD, Haruhiko Asano, MD, and Yuji Yokote, MD, Saitama, Japan
}

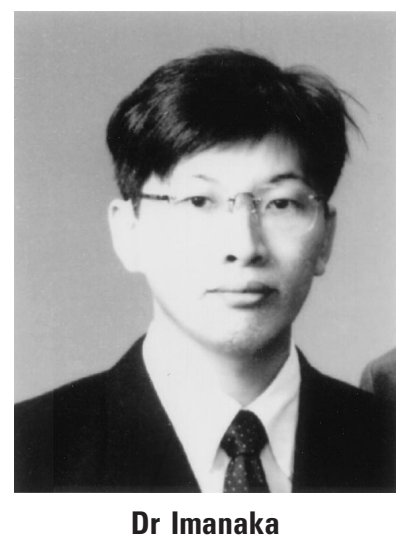

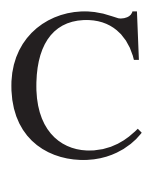

ontroversy exists as to the optimal management of acute Stanford type A aortic dissection with an intimal tear beyond the aortic arch (IIId-AAD). ${ }^{1}$ Usually, isolated transcatheter repair with a stent graft is not indicated because the position of the intimal tear is often unsuitable and because the potentially fatal dissection in the ascending aorta remains. Early and late complications may occur if the intimal tear is left untreated, but 1-stage surgery is too invasive, especially for patients with several comorbid conditions. With a simple contrivance during limited surgery, however, IIId-AAD can be managed more steadily and less invasively.

\section{Clinical Summary}

In a 54-year-old hypertensive woman, an acute myocardial infarction developed in the right ventricle and the inferior wall of the left ventricle. Close examination revealed that the ostium of the right coronary artery was totally obstructed because of aortic dissection. Severe low-output syndrome, recurrent ventricular fibrillation, and complete atrioventricular block were observed. Pericardial effusion was absent, and the false lumen was occluded with thrombi. An intimal tear was identified in the proximal descending aorta, appearing as an ulcer-like projection (Figure 1, A). Another tear was presumed to exist in the aortic root because contrast material was injected into the false lumen during right coronary arteriography. Medical treatment was initially begun. Because both intimal tears posed a threat to this middle-aged patient, replacement of the ascending aorta and the aortic arch, implantation of a stent graft into the proximal descending aorta, and coronary artery bypass

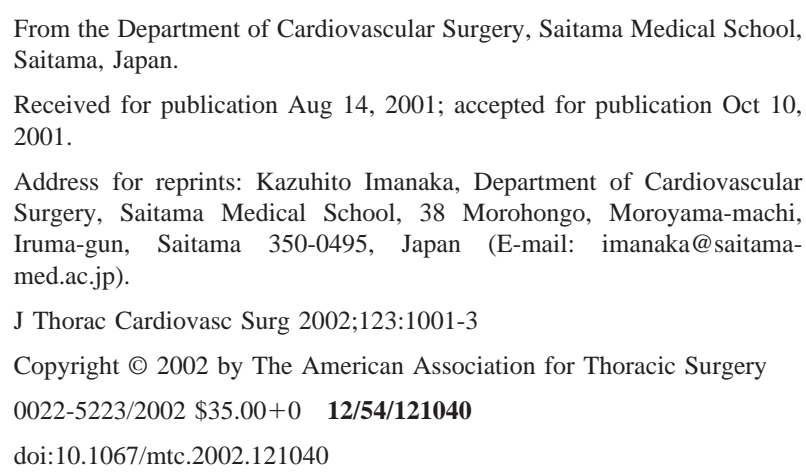

grafting $(\mathrm{CABG})$ were scheduled. Several days later, the ulcer-like projection was noted to have grown, but liver dysfunction occurred during conservative treatment. To avoid serious liver damage, we selected a 2-stage repair strategy and minimized the duration of visceral organ ischemia. The first stage was $\mathrm{CABG}$ with replacement of the ascending aorta alone. The second stage was transcatheter closure of the ulcer-like projection with a stent graft. The ulcer-like projection was located in the minor curvature of the aorta, and therefore perigraft leakage might occur. Accordingly, a vascular prosthesis with one branch was used for replacement of the ascending aorta, and an aorta-left subclavian artery bypass was made with the use of that branch after the extracorporeal circulation was stopped. The left subclavian artery was ligated, and a sufficient margin for placement of the proximal end of the stent graft was obtained. Transcatheter closure of the enlarging ulcerlike projection was successfully performed about 2 weeks later (Figure 1, $B$ and $C$ ). The clinical course thereafter was uneventful.

\section{Discussion}

The optimal management for IIId-AAD is controversial. Acute dissection in the ascending aorta is a serious condition, which should usually be considered for surgical repair. A distant intimal tear is another difficult problem. The false lumen is sometimes occluded with thrombi at first. Especially when an intimal tear is evident, however, redissection often occurs and occasionally is fatal. If the tear remains patent, a significant number of patients later have aneurysmal dilatation of the aorta. ${ }^{2,3}$ Therefore, some surgeons have committed themselves to 1-stage repair for IIIdAAD (namely, simultaneous replacement of the ascending aorta, aortic arch, and proximal descending aorta). ${ }^{4}$ Clearly, closure of the intimal tear is desirable and this large-scale operation is appropriate in a selected group of patients. However, many patients with IIId-AAD are critically ill. Since 1992, 29 patients with IIId-AAD have undergone surgery at our institute. Eight $(28 \%)$ patients had a concomitant acute myocardial infarction resulting from involvement of the coronary arteries, and another 4 were in shock. Some patients had definitive or possible organ malperfusion. One-stage repair is likely to carry a prohibitively high risk for these patients.

There is an increasing body of evidence about the effectiveness of a stent graft in cases of aortic dissection. ${ }^{5,6}$ However, because the intimal tear is often located very close to the ostium of the left 

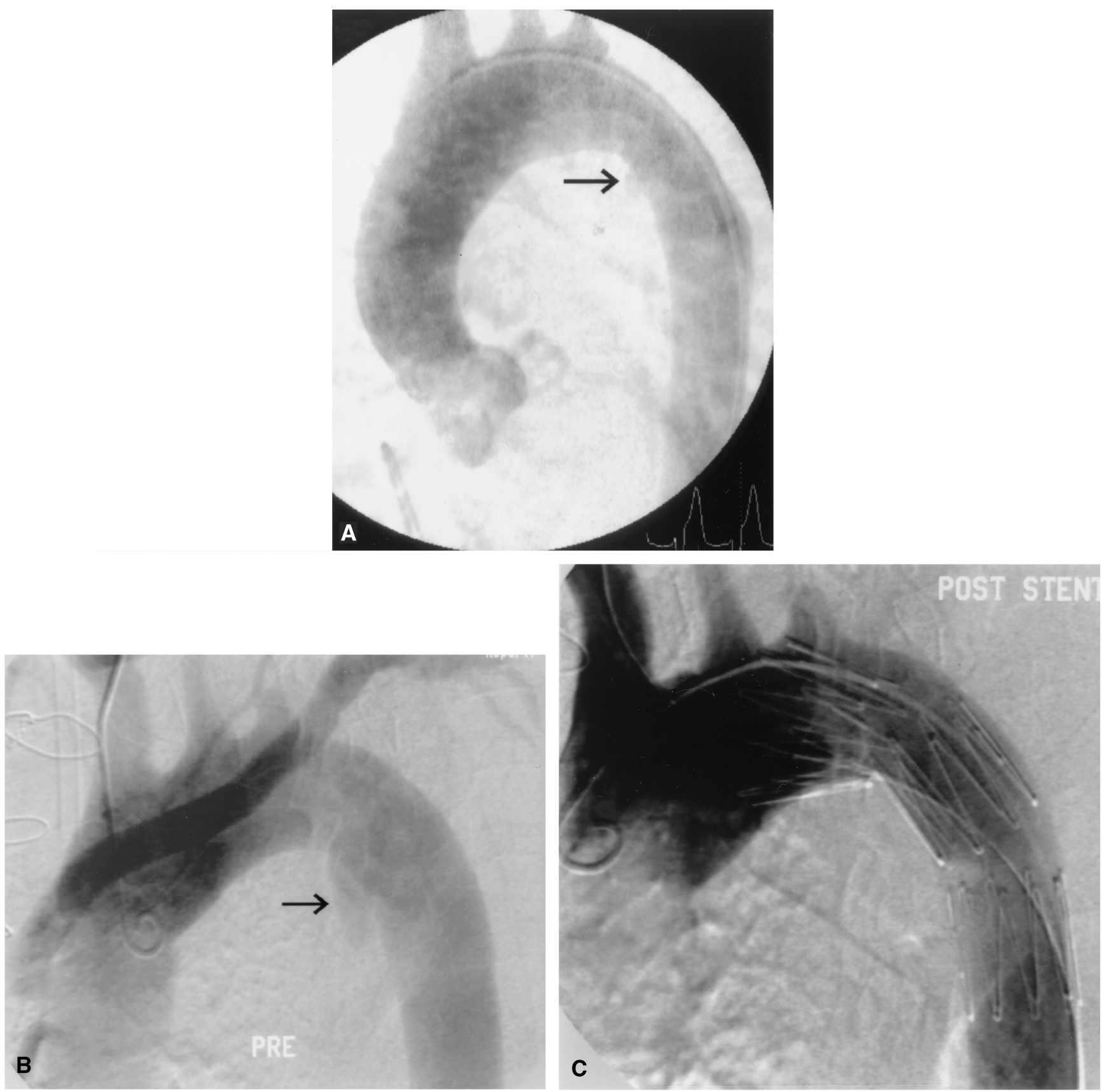

Figure 1. A, Digital subtraction angiogram of the aorta taken just after the onset of aortic dissection. A small ulcer-like projection was observed in the minor curvature of the proximal descending aorta (arrow). The right coronary artery was not opacified. B, Digital subtraction angiogram taken just before the transcatheter closure of the ulcer-like projection. The projection had markedly grown (arrow). The left subclavian artery had been ligated to provide a sufficient margin for placement of a stent graft. C, Transcatheter implantation of a stent graft was successfully performed.

subclavian artery or in the minor curvature of the aorta, simple transcatheter closure is difficult, and surgical stent-graft implantation $^{7}$ usually requires total aortic arch replacement to ensure closure of the intimal tear and to preserve the blood flow in the neck vessels. When surgery is indicated for patients with IIId-AAD, our 2-stage strategy can be a good alternative. Replacement of the ascending aorta with CABG can be accomplished with moderate hypothermia without or with systemic and cerebral circulatory 
arrest of short duration. This procedure is much less invasive than 1-stage repair. We made an aorta-left subclavian artery bypass using a branch of a vascular prosthesis and thus obtained a sufficient area of the aortic wall for anchoring a stent graft. Placement of this extra-anatomic bypass does not increase the surgical invasiveness and greatly facilitates the success of the transcatheter procedure and complete cure of IIId-AAD. The untouched intimal tear can be treated either immediately after the operation or after patient convalescence.

In the near future, this collaborative 2-stage repair strategy can be a viable option, not only for patients with IIId-AAD but also for those with other forms of Stanford type A dissection. We often encounter patients with a major intimal tear in the ascending aorta and a secondary tear in the proximal descending aorta. At a later stage, the secondary tear occasionally causes aneurysmal dilatation of the aorta. ${ }^{2,3}$ The present strategy can be well considered in such patients. Moreover, this strategy is also applicable to patients with significant cardiac disease and concomitant type B aortic dissection.

\section{References}

1. Reul GJ Jr, Cooley DA, Hallman GL, Reddy SB, Kyger ER III, Wukasch DC. Dissecting aneurysm of the descending aorta. Arch Surg. 1975;110:632-40.

2. Ergin MA, Phillips RA, Galla JD, Lansman SL, Medelson DS, Quintana CS, et al. Significance of distal false lumen after type A dissection repair. Ann Thorac Surg. 1994;57:820-5.

3. Bachet JE, Termignon JL, Dreyfus G, Goudot B, Martinelli L, Piquous A, et al. Aortic dissection: prevalence, cause, and results of late reoperations. J Thorac Cardiovasc Surg. 1994;108:199-206.

4. Kazui T, Tamiya Y, Tanaka T, Komatsu S. Extended aortic replacement for acute type A aortic dissection with the tear in the descending aorta. J Thorac Cardiovasc Surg. 1996;112:973-8.

5. Kato M, Matsuda T, Kaneko M, Kuratani T, Mizushima T, Seo Y, et al. Outcomes of stent-graft treatment of false lumen in aortic dissection. Circulation. 1998;98(Suppl):II-305-12.

6. Czermak BV, Waldenberger P, Fraedrich G, Dessl AH, Roberts KE, Bale RJ, et al. Treatment of Stanford type B aortic dissection with stent-graft: preliminary results. Radiology. 2000;217:544-50.

7. Kato M, Ohnishi K, Kaneko M, Ueda T, Kishi D, Mizushima T, et al. A new graft-implanting method for thoracic aortic aneurysm or dissection using a stented graft. Circulation. 1996;94(Suppl):II-188-93. 